\title{
The introduction of a lightweight mini vaporizer and malignant hyperthermia
}

\author{
Henry Rosenberg, MD • Frank Schuster, MD • \\ Stephan Johannsen, MD
}

Received: 30 September 2014/ Accepted: 31 October 2014/Published online: 15 November 2014

(C) Canadian Anesthesiologists' Society 2014

\section{To the Editor,}

The introduction of a lightweight mini vaporizer (AnaConDa ${ }^{\mathrm{TM}}$; Sedana Medical, Sweden) that can be used with an intensive care unit (ICU) ventilator has led to a resurgence of interest in the use of potent volatile agents as an alternative to intravenous agents for longterm sedation or for treatment of status asthmaticus in patients requiring tracheal intubation. In an editorial comment concerning the use of sevoflurane for treatment of status asthmaticus, ${ }^{1}$ Wasowicz and Jerath ${ }^{2}$ review the benefits of using volatile anesthetics for these reasons and mention several of the potential dangers of administration of potent volatile anesthetic agents outside the operating room environment. Unfortunately, what is omitted from their discussion is the mention of the risk of malignant hyperthermia $(\mathrm{MH})$, although the danger of MH is stated clearly in the report by Ruszkai et al. ${ }^{1}$ To underline this possibility, at the European Malignant Hyperthermia Group meeting in May 2014, Johannsen et $a .^{3}{ }^{3}$ reported on the development of MH in an ICU patient sedated with sevoflurane. In their case, the AnaConDa device was used for management of pneumonia in a 59-yr-old man and $\mathrm{MH}$ developed after five hours of sevoflurane anesthetic sedation. The signs included acute hemodynamic deterioration, metabolic and respiratory acidosis, increase of body temperature from $39.6-40.7^{\circ} \mathrm{C}$ over $30 \mathrm{~min}$, and elevation of creatine kinase

H. Rosenberg, MD ( $\varangle)$

Department of Medical Education and Clinical Research,

Saint Barnabas Medical Center, Livingston, NJ, USA

e-mail: hrosenberg@barnabashealth.org

F. Schuster, MD - S. Johannsen, MD

Department of Anaesthesia and Critical Care, University

of Wuerzburg, Wuerzburg, Germany to $3,450 \mathrm{U} \cdot \mathrm{L}^{-1}$. Fortunately, the clinicians recognized the signs of $\mathrm{MH}$ and treated with dantrolene, and the patient survived. A subsequent in vitro contracture test substantiated the clinical diagnosis of $\mathrm{MH}$.

Although only low concentrations of potent volatile agents are used to achieve sedation in the ICU, the risk of developing $\mathrm{MH}$ still exists, and appropriate therapy with dantrolene and supportive care must be immediately available. Because early symptoms of developing $\mathrm{MH}$ crisis are rather non-specific and can be misleading to other more frequent diagnoses, e.g., sepsis, the awareness of $\mathrm{MH}$ is crucial for ICU physicians of any medical specialty wherever volatile anesthetics are applied.

It is recommended that, when $\mathrm{MH}$ occurs as a result of sedation with volatile anesthetics, the details should be reported to the appropriate MH registry or similar database. Certainly, the Malignant Hyperthermia Association of the United States (www.mhaus.org) as well as the European Malignant Hyperthermia Group (www.emhg.org) would be interested in learning of such cases.

Conflicts of interest None declared.

\section{References}

1. Ruszkai Z, Bokretas GP, Bartha PT. Sevoflurane therapy for lifethreatening acute severe asthma: a case report. Can J Anesth 2014; 61: 943-50.

2. Wasowicz M, Jerath A. Expanding the use of volatile anesthetic agents beyond the operating room. Can J Anesth 2014; 61: 905-8.

3. Johannsen $S$, Mogele $S$, Roewer $N$, Schuster $F$. Malignant hyperthermia on ICU-sudden attack of the "snake". BMC Anesthesiology 2014; 14(Suppl 1): A11. 


\section{Reply}

We sincerely thank Drs. Rosenberg, Schuster, and Johannsen for their helpful comments. The case report published by Drs. Schuster and Johannsen indicates that malignant hyperthermia $(\mathrm{MH})$ may occur as a complication of volatile-based sedation in the intensive care unit (ICU). Anesthesiologists are highly knowledgeable about this syndrome, and thus, it is our responsibility to expand awareness of this rare condition to ICUs staffed by physicians with diverse training backgrounds. For intensive care physicians, the differential diagnosis for changes in temperature, hemodynamics, and hypercarbia can be highly complex and confounded with the more commonly seen problems of sepsis or acute respiratory distress syndrome. We appreciate highlighting the MH case secondary to sedation using sevoflurane, which well illustrates the rapid clinical and laboratory changes consistent with this syndrome. ${ }^{1}$

We currently lack the ideal sedative for our critically ill patients. As indicated, even low doses of volatile anesthetics can trigger $\mathrm{MH}$; however, this complication still remains rare when compared with the $1 \%$ risk of the potentially fatal propofol infusion syndrome and the contribution of benzodiazepines to ICU-related delirium that affects up to $80 \%$ of patients. ${ }^{2,3}$ Undoubtedly, we support reporting confirmed cases to the appropriate $\mathrm{MH}$ registry to improve our awareness of the incidence of this complication. Furthermore, it is important to expand the education of our ICU colleagues about this syndrome and to consider $\mathrm{MH}$ algorithms and the availability of dantrolene within ICUs that use volatile-based sedation.

\section{Conflicts of interest None declared.}

\section{References}

1. Schuster F, Moegele S, Johannsen S, Roewer N. Malignant hyperthermia in the intensive care setting. Crit Care 2014; 18: 411.

2. Roberts RJ, Barletta JF, Fong JJ, et al. Incidence of propofolrelated infusion syndrome in critically ill adults: a prospective, multicenter study. Crit Care 2009; 13: R169.

3. Girard TD, Pandharipande PP, Ely EW. Delirium in the intensive care unit. Crit Care 2008; 12(Suppl 3): S3.

Marcin Wasowicz MD, PhD

Angela Jerath MD

Department of Anesthesia and Pain Management, Toronto General

Hospital, Toronto, ON, Canada

E-mail: marcin.wasowicz@uhn.on.ca 